\title{
Samarbeid og svikt innen behandlingssystemet
}

\author{
Ved Nils Retterstøl
}

Det er vanlig å regne med at over $90 \%$ av dem som tar sitt liv har en psykiatrisk lidelse, hyppigst av depressiv eller personlighetsfiksert karakter, evt. kombinert med rusmiddelproblemer. Det sier seg da selv at mye kan gjøres ved tidlig og rett diagnose ved slike lidelser og bedrede behandlingstilbud. Det er mange muligheter for suikt $i$ behandlingskjeden - og muligheter til bedring.

\section{Pasienter, pårørende og omgivel- sene kan søke behandling tidligere}

For at det skal skje må tilgjengeligheten til leger, og ikke minst den psykiatriske helsetjeneste, giøres lettere. Terskelen for å få hjelp må gjøres lavest mulig. Det er også viktig at folkeopplysningen om selvmord heves. Noe må læres om slike problemer på skolen. Nøktern opplysning må gis gjennom mediene og opplysningsskrifter.

\section{Legen og behandlerne ellers kan bli flinkere til å stille diagnosen depre- sjon og vurdere selvmordsfare}

Pasienter har ved en legekonsultasjon lett for å legge hovedvekten på evt. somatiske symptomer eller livsproblemer, slik at legen kan avledes hvis han ikke gir tid eller anledning til å kartlegge en evt. depresjon og ikke minst stiller spørsmål om suicidaltanker direkte.

Dette er så meget viktigere når man vet at om lag $80 \%$ av dem som tar sitt liv har gitt hint om det på forhånd, og ca $70 \%$ har konsultert lege i løpet av de siste måneder før selvmordet. Heving av kompetansenivået i suicidologi, men også i depresjonslære, misbruksproblematikk og psykiatrisk diagnostikk generelt vil være en vesentlig selvmordsforebyggende faktor, likeså i moderne medikamentell antidepressiv behandling og psykoterapeutiske metoder. Men opplæringsprogrammene må gjentas med mellomrom, kunnskaper fornyes og motivering s $\varnothing$ kes opprettholdt.

\section{Forbindelseslinjer mellom primaer- helsetjenesten og sekundaerhelse- tjenesten må forbedres}

Det må bli lettere for allmennpraktikere å få pasienter vurdert, også med hensyn til suicidalitet, av spesialister innen det distriktspsykiatriske senter, poliklinikk eller annet ambulant tilbud, inkludert privatpraktiserende spesialister i psykiatri eller klinisk psykologi. Det bør foregå muntlig og skriftlig kontakt om pasientene, og epikriser etc. må raskt utveksles.

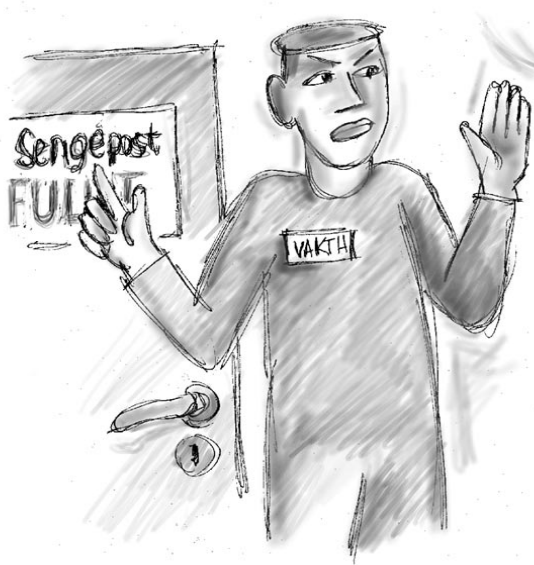

Innleggelsesmuligheter må gjøres lettere innen psykiatrien

Innen indremedisin, kirurgi etc. blir pasientene omgående mottatt som $\varnothing y e-$ blikkelig hjelp, og denne servicen oppfattes som god, mens behandlingen etterat den livreddende behandlingen er utført ofte svikter, noe som senere belyses. Innen psykiatrien er det blitt tiltagende mer vanskelig å bli innlagt. I vårt land har nedbyggingen av de psykiatriske institusjoner gått for raskt og for langt, og oppbyggingen av tilbud utenom for langsomt og kommet for kort. I de fleste fylker er det mangel på sengeplasser, noe som fører til en un $\varnothing$ dig sterk "siling" av pasientinntaket. Selv om suicidalitet gir indikasjon for фyeblikkelig hjelp, må innleggende leger ofte bruke urimelig lang tid til parlamentering og argumentering overfor vakthavende leger ved sykehusavdelinger. Dette kan føre til at de gir opp i en kamp som krever mer ressurser og tid enn de synes de har i sin travle hverdag. Selv om sykehuset, i mangel av plass, må gi tilbud om en ambulant vurdering, er det ofte ikke nok. Bedring av plasssituasjonen i psykiatriske institusjoner vil være et vesentlig suicidalforebyggende tiltak. Det vil også bedre muligheten til at pasienten kan gis et bedre og lengre sykehusopphold. Etter en suicidal krise vil behovet for tid til å ta seg inn igjen og bearbeide sin livssituasjon i høy grad være til stede. Tid er i psykiatrien en meget viktig behandlingsressurs.

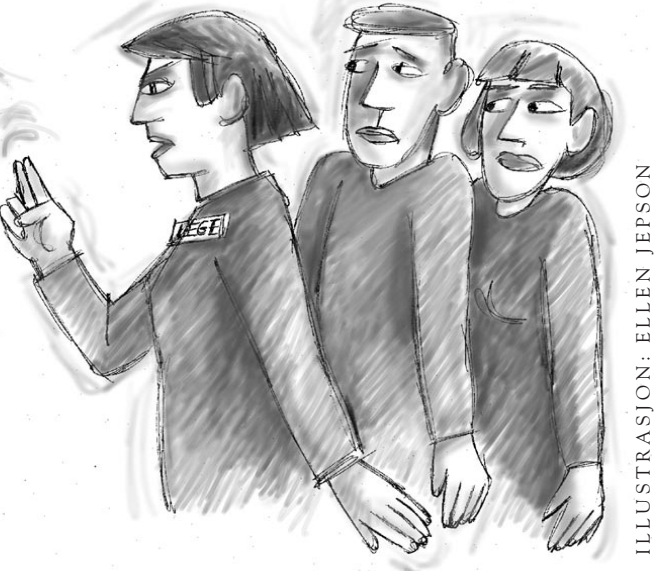

Behandlingstilbudene ved de somatiske avdelinger må forbedres

Mens den livreddende behandlingen gjerne er god, er behandlingen etter at pasienten neste dag er våknet opp og vil ut, langt svakere. I et norsk materiale (Berntsen og Husby 1994) viste det seg at det hos en tredjedel av de pasientene som var innlagt etter intoksikasjon, ikke var mulig å finne dokumentasjon for at pasienten var tilbudt en samtale om selvmordsfors $\varnothing$ ket i l $\varnothing$ pet av innleggelsen. Legens oppmerksomhet hadde ensidig konsentrert seg om somatiske behandlingsmetoder.

Enhver selvmordsfors $\varnothing$ ker bør vurderes som et menneske i nød, i en fastlåst livssituasjon, eller med en psykiatrisk lidelse. Han eller hun burde derfor ha rett til psykiatrisk unders $\varnothing$ kelse og behandling. Et forlenget opphold på en dag eller to, med motivasjonsbearbeidelse, burde være en selvfølge. Det er godt mulig situasjonen ved våre sykehus ikke er bedre enn referert ovenfor. I Sverige viser en fersk unders $\varnothing$ kelse (Runeson og medarbeidere 1994) at det ved de fleste sykehus er utarbeidet skriftlige retningslinjer for behandling av selvmordsfors $\varnothing$ kere, og at bortimot alle selvmordsfors $\varnothing$ kere innlagt i somatisk avdeling for $\varnothing$ yeblikkelig hjelp blir vurdert av lege fra psykiatrisk avdeling. Det burde være en målsetting også hos oss. 
Den såkalte Bærumsmodellen kan med fordel tilpasses andre sykehus, og er i modifisert form innført flere steder. Etter denne modellen făr alle selvmordsfors $\phi$ kere behandlet ved sykehuset et tilbud om evaluering med henblikk på oppfølgingstiltak. Teamet som har vært i sving fra 1983, består av sykepleier, sosionom, psykiater fra sykehuset i samarbeid med tilsvarende team pluss psykolog fra Bærum helseråd/helseetat. Omtrent halvparten henvises til helseetaten, mens resten henvises til annen behandlingsinstans. Burmo og medarbeidere (1990) har beskrevet dette programmet, som også er beskrevet i det norske handlingsprogram for forebyggelse av selvmord (1995). Det er utarbeidet en veileder for det forebyggende arbeid etter Bærumsmodellen (Dieserud og medarbeidere 1993).

Det er nødvendig med utdannelsesprogrammer for personale som arbeider i somatiske akuttavdelinger. Forskning har vist at personale ved intensivavdelinger gjerne har en relativt avvisende holdning til selvmordsforsøkere (Ramon og medarbeidere 1975, Wasserman 1986). Det er rimeligvis frustrerende for mennesker som er intenst opptatt av å berge liv, å møte mennesker som tvertimot gjør sitt beste for å ta sitt liv. Wasserman (1986) har vist at slike negative holdninger er mer uttalt i somatiske enn i psykiatriske akuttavdelinger. Skal slike holdninger endres, må det gis innføring i grunnprinsipper i suicidologi, og det må gis fortløpende veiledning. Bedre opplæringsprogrammer, bedre veiledning vil være sentrale nøkkelord.

\section{Forbedringer må gjøres i behand- lingstilbudene i de psykiatriske institusjonene. Utarbeidelse av fast instruks ved suicidalitet.}

Vi har allerede omtalt svikten i inntakssystemet og i den liggetid det gis til behandling av de psykiatriske pasientene. Mye kan fortsatt gjøres for å bedre innholdet i behandlingen. Det gjelder både den medikamentelle, den psykoterapeutiske, miljøterapeutiske og sosiale behandlingen av den enkelte pasient. Her er ikke stedet for å belyse dette i detalj. Tendensen i norsk psykiatri har vært den sektoriserte psykiatri, med opptakskriterier etter bosted. I fremtiden tror jeg behandlingen vil bli langt mer differensiert og spesialisert ut fra sykdomstilstand og funksjonsnivå, og da vil mer spisskompetanse innenfor de forskjellige lidelsers patologi og terapi utvikle seg. Vi ser det allerede i dag, og den utvikling vil fortsette. Vi vil imidlertid neppe trenge egne spesialiserte selvmordsfors $\varnothing$ ksenheter. Selvmordsfors $\varnothing$ kere finner vi innenfor de fleste psykiatriske lidelser, og de bør behandles i henhold til utgangslidelsen. På landsbasis kan det kanskje være $\varnothing$ nskelig med én spisskompetanseavdeling for pasienter der suicidalproblematikken er særlig vanskelig. Men faste retningslinjer for pasienter med suicidal atferd bør utarbeides ved alle psykiatriske institusjoner.

God kommunikasjon er et nøkkelord. Alle som omgås pasienter, bør være orientert om evt. suicidalfare.

Personalskifte, visitt-tid, weekend og permisjoner er risikotider.

Særdeles viktig er det med formidling av suicidalitet fra skift til skift, og ikke minst nattskift. Det kan være nødvendig å beskytte pasienten, ved å fjerne kniver, sakser mv., ved sikring av vinduer og inntak av medisiner under tilsyn. Dessuten bør fast avtale om tilsyn ved selvmordsfare opprettes i ethvert tilfelle.

Forf $\phi$ lging/frimerke: Man skal til enhver tid se hvor pasienten er og hva pasienten gjør, om mulig holde фyekontakt.

Fastvakt: Til enhver tid må fastvakten vite hvor pasienten er og hva han gjør.

Hyppig tilsyn: Slikt skal defineres, f.eks. som hvert 5. minutt, hvert 10. minutt, hvert kvarter osv.

Tett oppf $\phi$ lging: Et personalmedlem har ansvar for til enhver tid å vite hvor pasienten befinner seg.

Ikke utgang: Pasienten skal holde seg i avdelingen.

Utgang med f $\phi$ lge: Pasienten får forlate avdelingen, men bare i følge med en fra personalet.

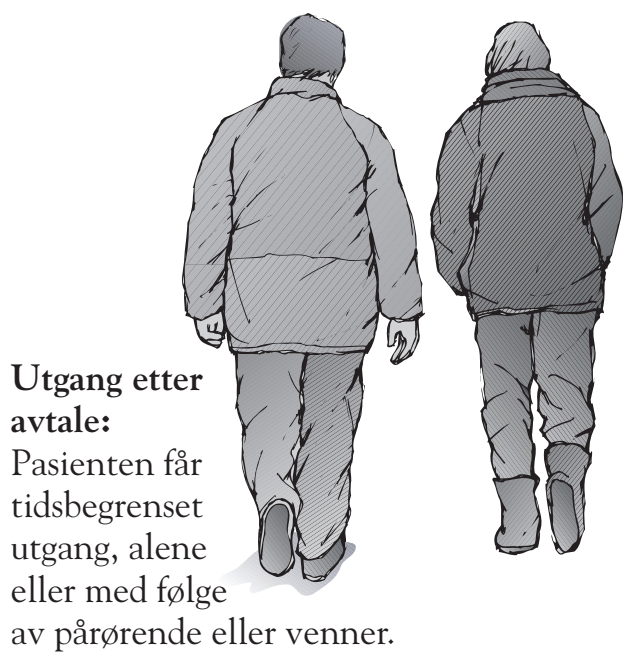

Faste retningslinjer $b \phi r$ utarbeides ved hvert sykehus.

Ved suicidalitet $b ø r$ behandlingstiden gjøres noe lengre enn der suicidalitet ikke synes å være til stede. Utskrivning b $\phi \mathbf{r}$ forberedes grundig. Ettervern må tilrettelegges, faste avtaler gis, og ettervernet $b \phi r$ minst vare 1 år.

Ved etablering av ettervern må dette gjøres i grundig og nært samarbeid med primærhelsetjenesten - som ofte overtar hele ettervernet og deler av det - og sekundærtjenesten (distriktspsykiatrisk senter, privatpraktiserende spesialister), og en samarbeidslinje disse imellom - og mellom disse og sykehuset - må etableres. Nøkkelordet er god kommunikasjon og klare linjer for oppgave- og ansvarsfordeling.

En oppgave som ofte fors $\varnothing$ mmes, er å bringe de pårørende inn i en samarbeidssituasjon, orientere dem og gi dem oppfølging og råd. Det er dem som bærer de daglige byrder, og som er pasientens nærmeste samarbeidspartnere.

De pårørende bør bringes inn på alle tre behandlingsnivåer.

\section{Bedre hjelp må gis til etterlatte etter selvmord}

Det er en klart $\varnothing \mathbf{k t}$ selvmordsrisiko for etterlatte, der et selvmord har skjedd.

I årrekker har psykiatrien fors $\varnothing \mathrm{mt}$ denne gruppen, som det må gis bedre tilbud til. Behandling av etterlatte etter selvmord har vært kalt "postvention" (Shneidman 1973). Det bør være den etterlattes rett å få samtale med en fagperson om dette, få anledning til å gi uttrykk for sine frustrasjoner, aggresjoner og selvbebreidelser - og få disse bearbeidet. I dag blir dette arbeidet i de færreste tilfeller grundig utført. Psykiatrien bør skjerpe seg på dette området. Retningslinjer for slikt etterarbeid er bl.a. gitt av Dunne (1992). 


\section{forts. fra forrige side}

Disse er også omtalt i boken Selvmord (Retterstøl 1995). I Norge har man i enkelte byer og tettsteder egne opplegg for mennesker som har mistet sine i selvmord. Foruten fra helsetjenesten, kan hjelp gjerne gis fra de enkelte menigheter. Det er et klart behov for bedre behandlingsopplegg for denne vanskeligstilte gruppe av mennesker. En egen landsoversikt over sorggrupper, deriblant sorggrupper for etterlatte etter selvmord, fins på Internettsidene til Seksjon for selvmordsforskning og -forebygging, under Etterlatte.

\section{Avslutning}

Dette nummer av tidsskriftet vårt er viet psykiatriske lidelser, og denne artikkelen har satt fokus på forebyggende tiltak mot selvmord i denne pasientgruppen. Vi har konsentrert oss om problemer og svikt i behandlingsopplegget. Artikkelen har derved i utgangspunktet en negativ slagside. Men la oss ikke glemme det entusiastiske og slitsomme arbeidet som utføres av de mange helsearbeidere, og den påkjenningen arbeidet med suicidale pasienter er for de fleste av oss. Det krever mye av oss som mennesker og medmennesker, og kan være med å gi noen og hver utbrenthetssyndrom. Men arbeidet innebærer også mange gleder og oppmun- tringer. Vi trenger imidlertid "påfyll” skal vi holde ut. Slikt påfyll får vi fra takknemlige pasienter vi hjelper et stykke på vei, - og vi får det ved opplæringsprogrammer, veiledning, kollegialt samarbeid og ved kompetanseheving.

Selv om det ikke alltid slår til, er vår rettesnor: Selvmord kan forebygges.

\section{Litteratur:}

Berntsen G, Husby R: Behandling av selvmordsfors $\phi$ kere i en somatisk avdeling.

Tidsskr. Nor. Lægeforen. 1994; 114: 2374-2378

Burmo M, Borg SE, Dieserud G, Sveum BD: Selvmordsfors $\phi k$ i Bærum 1984-1988. Rapport om det oppf $\varnothing$ lgende arbeid etter selvmordsfors $\phi k$ i Bærum kommune.

Bærum kommune: Helseetaten, 1990

Dieserud G, Mathiesen KS, Dalgard OS: Veileder: selvmordsforebyggende arbeid: Bærumsmodellen Oslo: Senter for sosialt nettverk og helse, 1993

Dunne EJ: Following a suicide postvention.

I: Bongar B: Suicide, guidelines for assessment, management, and treatment.

New York: Oxford University Press, 1992

Prosjektplan og handlingsplan mot selvmord 1994-1998. Skriftserie 4-95.

Oslo: Statens helsetilsyn, 1995

Ramon S, Bancroft HJ, Shirmshire M: Attitudes towards self-poisoning among physicians and nurses in a general hospital Br. J. Psychiatry 1975; 127: 257-264

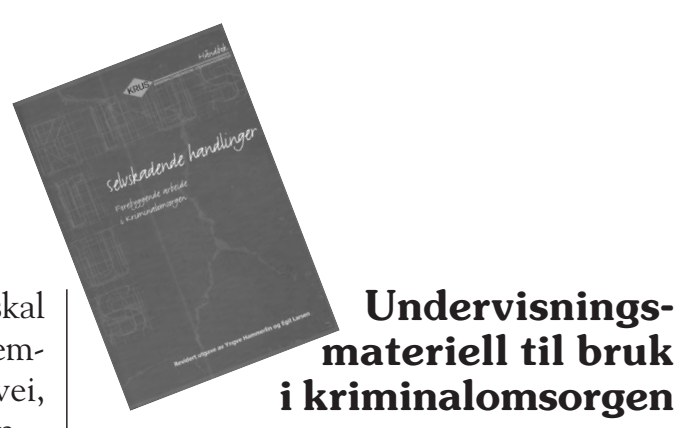

Hammerlin, Yngve / Larsen, Egil

Selvskadende handlinger.

Forebyggende arbeide i kriminalomsorgen. Håndbok.- rev utg. Oslo: KRUS - Kriminalomsorgens utdanningssenter, 1998. - $50 \mathrm{~s}$.

Manual. Underlag for klientsamtaler ved forebygging av selvskadende handlinger

Kortversjon. Selvmord(fors $\varnothing \mathbf{k}$ ) og selvbeskadigelse. En forenkling av håndboka/ en folder som kan puttes i skjortelomma.

Undervisningssettet kan bestilles fra KRUS v/Turid Midtbø, Pb 6138 Etterstad, 0602 Oslo, tlf: 230671 00, faks: 23067102.

(Omtale i neste nummer)

Retterst $\varnothing 1$ N: Selvmord

Oslo: Universitetsforlaget, 1995

Runeson B, Wasserman DW, Träskman-Bendz L, Agren H, Asberg M: Management of suicide attempters in psychiatric care in Sweden. Nord. J. Psychiatry 1994, 48: 117-120

Shneidman, Edwin S. The death of man. New York: Quadrangle Books, 1973

Wasserman DW: Attempted suicide - the patients' family, social network and therapy. Akademisk avhandling. Stockholm: Karolinska institutet, 1986

Robins E, Gassner S, Kayes J, Wilkinson RH, Murphy GE: The communication of suicidal intent: a study of 134 consecutive cases of successful (completed) suicide.

Am. J. Psychiatry 1959; 115: 724-733

*Rossow I, Amundsen A: Alcohol abuse and suicide: a 40-year prospective study of Norwegian conscripts. Addiction 1995; 90: 685-691

Sundby P: Alcoholism and mortality Oslo: Universitetsforlaget, 1967

Wasserman D, Värnik A, Eklund G: Female suicides and alcohol consumption during perestroika in the former USSR

Acta Psychiatr. Scand 1998; 98 (suppl 394): 26-33

Wasserman D, Värnik A, Eklund G: Male suicides and alcohol consumption in the former USSR Acta Psychiatr. Scand 1994; 89: 306-313

Åsgård U: Suicide among Swedish women. A psychiatric and epidemiological study. Stockholm: Karolinska Institutet, 1990

*Ingeborg Rossow har skrevet artikkelen "Alkohol og selvmord" $i$ et tidligere nr. av dette tidsskriftet, som den interesserte leser henvises til: Rossow I: Alkohol og selvmord.

Nytt i suicidologi 1997; 1: 12-14 